\title{
Patient-physician communication about end-of-life care for patients with severe COPD
}

\author{
J.R. Curtis*,\#, R.A. Engelberg*,\#, E.L. Nielsen*, D.H. Au*, , D.L. Patrick ${ }^{\#}$
}

Patient-physician communication about end-of-life care for patients with severe COPD. J.R. Curtis, R.A. Engelberg, E.L. Nielsen, D.H. Au, D.L. Patrick. (C) ERS Journals Ltd 2004.

ABSTRACT: Since patients with chronic obstructive pulmonary disease (COPD) infrequently discuss treatment preferences about end-of-life care with physicians, the goal of the present study was to identify which specific areas of communication about end-of-life care occur between patients with severe COPD and their physicians, and how patients rate the quality of this communication.

A total of 115 patients with oxygen-dependent COPD, identified in pulmonary clinics in three hospitals and through an oxygen delivery company, were enrolled in this study. A 17-item quality of communication questionnaire (QOC) was administered to patients, along with other measures, including satisfaction with care.

The patients reported that most physicians do not discuss how long the patients have to live, what dying might be like or patients' spirituality. Patients rated physicians highly at listening and answering questions. Areas patients rated relatively low included discussing prognosis, what dying might be like and spirituality/religion. Patients' assessments of physicians' overall communication and communication about treatment correlated well with the QOC. Patients' overall satisfaction with care also correlated significantly with the QOC.

In conclusion, this study identifies areas of communication that physicians do not address and areas that patients rate poorly, including talking about prognosis, dying and spirituality. These areas may provide targets for interventions to improve communication about end-of-life care for patients with chronic obstructive pulmonary disease. Future studies should determine the responsiveness of these items to interventions, and the effect such interventions have on patient satisfaction and quality of care.

Eur Respir J 2004; 24: 200-205.
*Division of Pulmonary and Critical Care Medicine, Dept of Medicine, School of Medicine, and ${ }^{\#}$ Dept of Health Services, School of Public Health and Community Medicine, University of Washington, and Health Services Research and Development, Dept of Veterans Affairs, Seattle, WA, USA.

Correspondence: J.R. Curtis, Division of Pulmonary and Critical Care, Box 359762, Harborview Medical Center, University of Washington, Seattle, Washington 98104 USA. Fax: 12067318584

E-mail: jrc@u.washington.edu

Keywords: Chronic obstructive pulmonary disease

communication

death

dying

end-of-life care

palliative care

Received: January 252004

Accepted after revision: April 142004

This study was supported by a Career Investigator Award from the American Lung Association and the American Lung Association of Washington (J.R. Curtis).
Chronic obstructive pulmonary disease (COPD) is a leading cause of morbidity and mortality worldwide, and age-adjusted mortality continues to increase while mortality from other leading causes of death, including cardiovascular disease and cancer, has decreased [1, 2]. Among patients with life-limiting illnesses such as COPD, there are documented shortcomings in the current provision of end-of-life care [3]. Improving the quality of care for patients at the end of life has become a major goal of the medical community and the general public $[4,5]$. However, the recently updated Global Initiative on Chronic Obstructive Pulmonary Disease guidelines, assembled by an expert panel under the auspices of the National Heart Lung and Blood Institute and the World Health Organization, do not include recommendations on providing end-of-life care for patients with COPD, in large part because of an absence of data guiding such care. Data about providing high-quality end-of-life care would be beneficial given recent studies that suggest end-of-life care may be worse for patients with COPD compared to those with other diseases such as lung cancer [6, 7]. Although reasons for these differences are not clear, prior studies show that only a small proportion of patients with moderateto-severe COPD have discussed treatment preferences and end-of-life care issues with their physicians, and the vast majority of these patients believe their physicians do not understand their preferences for end-of-life care [8, 9]. Patients with COPD are more likely than patients with cancer or AIDS to express concern about the lack of education that they receive about their disease, treatment, prognosis and advance care planning [10]. It is possible that part of the reason that patients with COPD may receive lower quality end-of-life care is that patient-physician communication about end-of-life care may be less likely to occur, more difficult to conduct for patients with less certain prognosis or some combination of both.

In order to improve communication about end-of-life care for patients with COPD, it would be useful to identify the specific components of this communication that patients report are not occurring or occur poorly, in order to identify targets for future interventions. In this paper, the authors examine patient-physician communication amongst a cohort of patients with oxygen-dependent COPD, in order to identify specific areas of communication about end-of-life care that patients report are not occurring, and to identify specific areas of good and poor quality communication. 


\section{Methods}

\section{Participant recruitment and enrolment}

This study was conducted in Seattle (WA, USA) between July 1999 and June 2002. Patients were eligible if they were $\geqslant 18$ yrs, English speaking, had a diagnosis of COPD with airflow obstruction and had been prescribed oxygen therapy for continuous home use. Patients were excluded if they were not expected to use oxygen indefinitely or their mental status precluded participation. Patients were identified through ambulatory pulmonary clinics in three hospitals (university, county and veteran affairs (VA) teaching hospital) and through an oxygen delivery company. Two enrolment methods were used. At the county and university hospitals, a clinician familiar with the patient asked if he or she was willing to talk with study staff. At the VA medical centre and oxygen delivery company a letter was mailed to all patients on oxygen asking them to call a toll-free voice message if they were unwilling to participate; if they did not leave a message declining participation, they received a phone call from the study staff.

All interviews were completed as outpatients in a private setting, in physicians' offices or patients' homes. Each participating patient was also asked to identify the physician who was primarily responsible for taking care of his or her pulmonary disease. The Human Subjects Committee at the University of Washington approved all study procedures and patients provided written consent for participation.

\section{Quality of communication questionnaire development}

The quality of communication questionnaire (QOC) was adapted from a prior version developed through focus groups of patients with AIDS [11] and validated in a cohort of patients with advanced AIDS [12]. This initial questionnaire had four items and, although it demonstrated construct validity, it had an important ceiling effect in which $50 \%$ of physicians were assigned the highest possible score by their patients. In order to improve the instrument's performance and ability to discriminate specific components of communication about end-of-life care, additional communication items concerning end-of-life care were identified through a series of qualitative studies involving patients with COPD, cancer and AIDS $[10,13,14]$. In these studies, patients were asked to identify the components of physician skill at providing end-of-life care, and transcripts were analysed using the methods of grounded theory to identify components of communication about end-of-life care important to patients $[15,16]$. The relevance to patients with severe COPD was confirmed by conducting three additional focus groups comprised of 15 patients with oxygen-dependent COPD. During these three focus groups, patients were asked to identify the skills important to them in patient-physician communication about end-of-life care, and subsequently shown the 17 items identified from the prior studies. These three focus groups were audiotaped and transcribed verbatim by a transcriptionist experienced with the qualitative research process. Using the principles of content analyses [17], investigators reviewed the transcripts to confirm the items previously identified and searched for additional components of quality communication. Based on the prior studies and these focus groups, 17 items were identified and then confirmed. Patients are asked to rate how good their doctor was at each of the communication skills on a scale of $0-10$, with " 0 " indicating "the very worst" and "10" indicating "the very best". Patients were also offered the response option of "my doctor did not do this", which allowed them the opportunity to leave an item unrated when it did not occur. A summary score was created by adding the scores for the 17 individual items, dividing by the number of items answered by the patient and multiplying by 10 to provide a score ranging $0-100$. No values were substituted for missing (including "don't know" and "refusal" responses) or "doctor did not do" responses. A trained interviewer administered this questionnaire; patients were provided with a copy of the instrument to read along if they chose to do so. The questionnaire is available online [18].

\section{Additional questions}

In addition to the QOC, a number of healthcare communication items were included. These were: 1) two questions concerning physician-patient communication in general; 2) two questions assessing overall satisfaction with healthcare; and 3) one question assessing physician comfort talking about dying. These questions were included to provide measures of comparable constructs to those assessed by the QOC.

Patient demographic data collected included age, sex and race. Patients also completed the Center for Epidemiologic Study - Depression (CES-D) survey, a validated instrument for assessing depressive symptoms, and the CES-D was scored according to standard methods [19]. As previously validated, a CES-D score of 16 was used as the dichotomous cut-off point, with higher and lower scores indicating presence or absence of depression, respectively [20]. In addition, patients were asked to report their duration of time on oxygen therapy and co-existing illnesses. Each patient's forced expiratory volume in one second (FEV1) was obtained using a portable spirometer according to American Thoracic Society standards [21]. Alternatively, if patients consented to medical record review, FEV1 values were obtained from medical records. Physician demographic data was collected using surveys sent to physicians identified by patients as being primarily responsible for care of their lung disease. These data included age, sex, years in practice, years caring for the patient, specialty and subspecialty training, and number of patients treated with COPD.

\section{Statistical analyses}

QOC items were examined using descriptive analyses including $\%$ missing, $\%$ "doctor did not do this", $\%$ respondents scoring $0, \%$ respondents scoring 10 , means, SD and ranges. The per cent of patients endorsing items with a score $\leqslant 5$ was also identified. The relationship between the QOC summary score, and both patient and physician characteristics was assessed using Spearman's correlation coefficient for continuous variables, Kruskal-Wallis test for categorical variables and the Mann-Whitney test for dichotomous variables. The relationship between the QOC summary score and other variables that were expected to measure similar, but not identical, constructs were assessed, including: 1) general satisfaction with care; and 2) overall ratings of communication. Non-parametric statistics were used due to the skew in the QOC distribution. Analyses were confirmed using linear regression; since statistical associations were identical, only the non-parametric statistics are presented. Statistical significance values were set at $p \leqslant 0.05$.

\section{Results}

At the two study sites where research staff were present in the clinics, 78 eligible patients were identified and 50 enrolled 
for a participation rate of $64 \%$. At the two study sites where patients were sent a mailing describing participation, 217 eligible patients were identified and 68 enrolled for a participation rate of $31 \%$. Overall, out of the 295 eligible patients contacted and asked to participate in a 1-h in-person interview, 118 were enrolled for $40 \%$ participation. Out of the 118 enrolled patients, 115 completed the interviews and three were unable due to fatigue. Questionnaires were mailed to physicians for 102 patients (physicians could not be contacted for 13 patients). Questionnaires were returned from physicians for 88 patients, giving a response rate from physicians of $86 \%$. There were 55 unique physicians: 39 physicians had one patient, eight physicians had two patients, three physicians had three patients, two physicians had four patients, and three physicians had five or six patients. Demographic characteristics of the patients and physicians are shown in table 1. Patients had a mean age of $67 \mathrm{yrs}$ and a mean predicted FEV1 value of $29 \%$. Approximately three-quarters of patients were male and $84 \%$ were Caucasian. Over $80 \%$ of the physicians were trained in internal medicine and almost $60 \%$ had training in pulmonary medicine.

Table 1.-Participant characteristics

\begin{tabular}{|c|c|c|}
\hline Participant characteristics & Patients & Physicians \\
\hline Subjects $n$ & 115 & 55 \\
\hline Age yrs & $67.2 \pm 9.5$ & $43.4 \pm 9.0$ \\
\hline Duration oxygen use months & $35.0 \pm 24.6$ & \\
\hline FEV1 \% pred & $29.0 \pm 14.3$ & \\
\hline Time since med school graduation yrs & & $16.4 \pm 10.2$ \\
\hline Male & $72(83)$ & $80(45)$ \\
\hline White & $84(96)$ & $84(46)$ \\
\hline Married or with partner & $46(53)$ & \\
\hline \multicolumn{3}{|l|}{ Education } \\
\hline$\leqslant 8$ th grade & $4(5)$ & \\
\hline $9-12$ th grade & $39(45)$ & \\
\hline$>12$ th grade/some college & $34(39)$ & \\
\hline College degree & $12(14)$ & \\
\hline$>$ College & $9(10)$ & \\
\hline \multicolumn{3}{|l|}{ Health insurance } \\
\hline Private, prepaid & $21(24)$ & \\
\hline Government programme & $94(108)$ & \\
\hline None & $1(1)$ & \\
\hline \multicolumn{3}{|l|}{ Monthly income } \\
\hline$\leqslant \$ 500$ & $2.6(3)$ & \\
\hline$\$ 501-\$ 1500$ & $43.5(50)$ & \\
\hline$\$ 1501-\$ 3000$ & $20.9(24)$ & \\
\hline$\geqslant \$ 3001$ & $22.6(26)$ & \\
\hline \multicolumn{3}{|l|}{ Type of practice } \\
\hline Solo or small group private & & $5.4(3)$ \\
\hline Group practice & & $14.3(8)$ \\
\hline $\mathrm{HMO}$ & & $10.7(6)$ \\
\hline VA clinic & & $42.9(24)$ \\
\hline University clinic & & $14.3(8)$ \\
\hline County hospital clinic & & $10.7(6)$ \\
\hline \multicolumn{3}{|l|}{ Specialty } \\
\hline Family practice & & $7.5(4)$ \\
\hline Internal medicine & & $82.1(46)$ \\
\hline Other & & $8.9(5)$ \\
\hline \multicolumn{3}{|l|}{ Subspecialty training ${ }^{\#}$} \\
\hline Pulmonary & & $58.9(33)$ \\
\hline Critical care & & $50.0(28)$ \\
\hline $\begin{array}{l}\text { COPD patients cared for } n \\
>200 \text { patients }\end{array}$ & & $446(25)$ \\
\hline
\end{tabular}

Data are presented as mean \pm SD or $\%$ (n). FEV1: forced expiratory volume in one second; HMO: health maintenance organisation; VA: veteran affairs; COPD: chronic obstructive pulmonary disease. ${ }^{\#}$ : respondents were able to endorse more than one subspecialty.
Description and measurement properties of the quality of communication items

The items of the QOC and their measurement properties are shown in table 2 . To assess specific items that patients report physicians do not perform, the proportion of patients that indicated "doctor did not do" for each item was examined. Endorsements indicating that the "doctor didn't do this" ranged from a low of $0 \%$ on three items to $88.7 \%$ on one item. There were four items that more than half of patients reported were not performed by their physicians. These included "talking about how long you have to live" (74.8\%), "talking about what dying might be like" (87.0\%), "talking with loved ones about what dying might be like" $(88.7 \%)$ and "asking about your spiritual or religious beliefs" (82.6\%).

In order to identify items on which physicians were rated most highly, the proportion of patients rating an item as 10 out of 10 was examined. All items had some respondents endorsing this maximum score. These endorsements ranged from a low of $3 \%$ of respondents on the item "how good is your physician at talking with loved ones about what dying might be like" to $59 \%$ of respondents on "how good is your physician at listening to what you have to say". The other items that were rated as 10 by $>50 \%$ of patients were "answering all questions about your illness" and "looking you in the eye".

To assess which items, when performed, were rated poorly, items for which at least one quarter of patients endorsing the item rated their physician as $\leqslant 5$ on the scale of $0-10$ were examined. These poorly performed items included "asking about your spiritual or religious beliefs" and "talking about how long you have to live."

\section{Measurement properties of the quality of communication summary score}

A summary score for the QOC was calculated as the average of all valid items and was then multiplied by 10 to give a score ranging $0-100$. The summary score was based on at least five valid responses out of a total of 17 items. The QOC summary score using this method was 87.4 with a SD of 14.9 and a range 8-100. There was no floor effect (individuals who scored their physician at 0 ) and $19 \%$ of patients gave their physician a score at the questionnaire's ceiling (a perfect score of 100) (table 2).

\section{Correlates of better quality communication}

There were no significant associations between the patient or physician characteristics in table 1 and the QOC summary score (data not shown). There was, however, a significant association between the QOC summary score and the burden of depressive symptoms as assessed by the CES-D. Using the dichotomous cut-off for depression for the CES-D, those with a CES-D score consistent with clinical depression at $\geqslant 16$ had a QOC summary score of 82.6 compared to those with a CES-D score $<16$ who had a significantly higher QOC summary score of $90.2(\mathrm{p}<0.001)$.

Patients' assessment of their overall ratings of physician communication skill and their general satisfaction with care were all associated with the QOC summary score. The patients' assessments of the physicians' overall communication were significantly correlated with the QOC summary score, as shown in table 3 . In addition, the patients' assessment of the physicians' comfort in talking about dying was also highly correlated with the QOC summary score. Finally, the patients' overall satisfaction with care was also significantly correlated with the QOC summary score. 
Table 2.-Quality of communication questionnaire (QOC) item characteristics

\begin{tabular}{|c|c|c|c|c|c|c|c|}
\hline QOC Items & $\begin{array}{c}\text { Missing }^{\#} \\
\%(\mathrm{n})\end{array}$ & $\begin{array}{c}\text { Doctor } \\
\text { didn't do } \\
\%(\mathrm{n})\end{array}$ & $\begin{array}{l}\text { Scoring } 0 \\
\text { out of } 10 \\
\%(n)\end{array}$ & $\begin{array}{l}\text { Scoring } 10 \\
\text { out of } 10 \\
\%(n)\end{array}$ & $\begin{array}{l}\operatorname{Mean} \pm \text { SD } \\
\text { score }^{\uparrow}\end{array}$ & Range & $\begin{array}{c}\text { Scoring } \leqslant 5 \\
\text { out of } 10 \\
\%(n)^{+}\end{array}$ \\
\hline Using words you understand & $6.1(7)$ & $2.6(3)$ & $0.0(0)$ & $39.1(45)$ & $8.76 \pm 1.46$ & $4-10$ & $5.7(6)$ \\
\hline Looking you in eye & $4.3(5)$ & $0.9(1)$ & $0.0(0)$ & $51.3(59)$ & $8.94 \pm 1.65$ & $3-10$ & $7.3(8)$ \\
\hline Including loved ones in treatment discussions & $6.1(7)$ & $37.4(43)$ & $0.0(0)$ & $27.8(32)$ & $8.85 \pm 1.67$ & $2-10$ & $6.2(4)$ \\
\hline Answering all questions about illness & $2.6(3)$ & $1.7(2)$ & $0.9(1)$ & $56.5(65)$ & $9.01 \pm 1.68$ & $0-10$ & $5.5(6)$ \\
\hline Listening to what you have to say & $1.7(2)$ & $0(0)$ & $0.0(0)$ & $59.1(68)$ & $9.05 \pm 1.56$ & $2-10$ & $5.3(6)$ \\
\hline Caring about you as a person & $6.1(7)$ & $0(0)$ & $0.9(1)$ & $47(54)$ & $8.82 \pm 1.74$ & $0-10$ & $8.3(9)$ \\
\hline Giving full attention & $1.7(2)$ & $0(0)$ & $0.0(0)$ & $56.5(65)$ & $9.07 \pm 1.56$ & $1-10$ & $4.4(5)$ \\
\hline $\begin{array}{l}\text { Talking about your feelings about getting } \\
\text { sicker }\end{array}$ & $3.5(4)$ & $43.5(50)$ & $0.0(0)$ & $23.5(27)$ & $8.46 \pm 2.05$ & $2-10$ & $14.8(9)$ \\
\hline Talking about details if you got sicker & $1.7(2)$ & $47.0(54)$ & $0.9(1)$ & $21.7(25)$ & $8.25 \pm 2.32$ & $0-10$ & $16.9(10)$ \\
\hline Talking about how long you have to live & $3.5(4)$ & $74.8(86)$ & $0.9(1)$ & $11.3(13)$ & $7.68 \pm 3.09$ & $0-10$ & $28.0(7)$ \\
\hline Talking about what dying might be like & $5.2(6)$ & $87.0(100)$ & $0.0(0)$ & $4.3(5)$ & $8.67 \pm 2.35$ & $3-10$ & $11.1(1)$ \\
\hline $\begin{array}{l}\text { Talking with loved ones about what dying } \\
\text { might be like }\end{array}$ & $6.1(7)$ & $88.7(102)$ & $0.0(0)$ & $2.6(3)$ & $9.00 \pm 1.26$ & $7-10$ & $0(0)$ \\
\hline $\begin{array}{l}\text { Involving you in treatment discussion about } \\
\text { your care }\end{array}$ & $5.2(6)$ & $47.8(55)$ & $0.9(1)$ & $17.4(20)$ & $8.39 \pm 2.11$ & $0-10$ & $13.0(7)$ \\
\hline Asking you about important things in life & $4.3(5)$ & $48.7(56)$ & $0.9(1)$ & $16.5(19)$ & $8.41 \pm 1.97$ & $0-10$ & $11.1(6)$ \\
\hline Respecting important things in your life & $8.7(10)$ & $21.7(25)$ & $0.9(1)$ & $37.4(43)$ & $8.94 \pm 1.77$ & $0-10$ & $8.8(7)$ \\
\hline Asking about spiritual, religious beliefs & $2.6(3)$ & $82.6(95)$ & $0.9(1)$ & $3.5(4)$ & $7.18 \pm 3.07$ & $0-10$ & $29.4(5)$ \\
\hline Respecting spiritual, religious beliefs & $17.4(20)$ & $46.1(53)$ & $0.0(0)$ & $19.1(22)$ & $8.50 \pm 2.45$ & $1-10$ & $16.7(7)$ \\
\hline $\begin{array}{l}\text { QOC summary score (transformed to } \\
0-100 \text { scale) }\end{array}$ & $1.7(2)$ & & $0.0(0)$ & $19.1(22)$ & $87.37 \pm 14.90$ & $7.50-100$ & $1.8(5)$ \\
\hline
\end{tabular}

${ }^{\#}$ : missing includes "don't know" and "refusal" responses; ${ }^{\top}$ : item scores on a scale of $0-10$ and summary score transformed to $0-100 ;{ }^{+}: \%$ based on number of valid responses.

\section{Discussion}

There has been increased emphasis on the importance of patient-physician communication about end-of-life care in the medical literature [22]. A number of excellent review articles have provided expert opinion concerning the delivery of bad news [23-27] and communication about palliative medicine [28], but there are limited empirical data that show how to improve this communication [26]. Prior qualitative studies of patients with severe COPD suggest that communication about end-of-life care and concerns about death are important to these patients $[10,29,30]$. In the current study, patients' ratings of the quality of specific areas of patient-physician communication about end-of-life care were examined. There were several areas of communication that patients rated highly, including listening to patients, attending to patients' concerns and answering patients' questions. Although these are general communication skills that extend beyond communication about end-of-life care, they have been demonstrated to be important to patients with life-limiting diseases, including COPD, in prior qualitative studies [10-14]. Identifying those aspects of communication that most physicians perform well provides positive feedback for physicians caring for patients with severe COPD and may be an important strategy for promoting end-of-life communication.

There were also a number of areas that physicians addressed poorly or not at all. These areas centre on difficult issues, such as being able to talk with patients about how long they have to live and what dying might be like. These tasks require that patients and physicians talk honestly about prognosis and death, and require that physicians educate patients about the nature of their disease. Prior research suggests that education about these issues is particularly important to patients with COPD [10]. Among patients with terminal or life-limiting illness, honest and straightforward information is paramount among communication needs [31]. In a large multi-centre study of patients with cancer, $87 \%$ reported wanting all possible information [32]. Despite the desire of many patients for full and truthful information, dramatic disagreement is often found between patients' and physicians' estimates concerning survival. Patients are more optimistic about their prognosis than their physicians, and

Table 3. - Quality of communication questionnaire (QOC) association with healthcare communication items, general satisfaction with care and comfort discussing dying

Spearman correlations with QOC score (p-value)

Communication items

How would you rate your treatment discussions that you have had with your physician?\#

Rate your doctor's overall communication ${ }^{\#}$

$0.68(0.0001)$

Satisfaction with care

How skilled and knowledgeable is your physician?

How would your rate the overall care you have received from your doctor? ${ }^{\#}$

$0.67(0.0001)$

Comfort discussing death

How comfortable is your doctor about talking about dying?\#

$0.24(0.01)$

$0.52(0.0001)$

$0.71(0.0001)$

\footnotetext{
\#: $1-10$ with $0=$ very worst and $10=$ very best; ${ }^{\top}: 1=$ not at all, $2=$ somewhat, $3=$ =quite, $4=$ very, $5=$ extremely.
} 
the physicians' estimates are more accurate [33]. In addition, some physicians report deliberately withholding information in response to patients' own assessments, as humane ways of preserving or fostering hope in their patients [34-36]. Further studies are needed to find ways to help physicians provide truthful disclosure about prognosis.

Another area that physicians did not address or addressed poorly was asking about patients' spiritual or religious beliefs. Prior studies suggest that the majority of patients want to discuss spiritual or religious issues with their physicians [37-39] and, in Europe, religion may be an important determinant of the care patients receive [40]. Several reviews suggest approaches that physicians can take in discussing religion with patients [41, 42], although empirical data about which specific techniques improve patient satisfaction are limited. The current study confirms this to be an area that many physicians do not discuss with their patients with COPD and, when they do discuss this area, patients rate the quality of these discussions relatively poorly.

Although there are no prior studies examining the quality of patient-physician communication about end-of-life care specifically for patients with COPD, there have been studies that have examined this communication among a general patient population or patients with cancer. Several qualitative studies have examined the quality of patient-physician communication about "do not resuscitate" orders for hospitalised patients [43], and communication between physicians and outpatients about advance directives [44, 45]. These studies found substantial short-comings in the communication skills of physicians, noting that physicians spend $75 \%$ of the time talking, and miss important opportunities to allow patients to discuss their personal values and goals of therapy. A recent randomised trial showed that an intensive 3-day communication skills workshop can improve oncologists' communication skills, as judged by experts viewing videotaped encounters with patients [46]. The goal of the current study was to use the perspective of patients with severe COPD to assess the quality of patient-clinician communication about end-of-life care and to determine the specific aspects of this communication most in need of improvement. If additional studies find this questionnaire to be reliable, valid and responsive to change, it may hold promise as an outcome measure for interventions to improve this communication. This report provides preliminary validation of this measure, assessing patient-physician communication about end-of-life care. The measure is a 17 -item questionnaire completed by patients in $<5 \mathrm{~min}$. This questionnaire correlated with measures assessing similar constructs, such as overall satisfaction with care and satisfaction with general communication. Future studies will be needed to assess the measurement characteristics of this questionnaire, including additional measures of reliability and validity, and to assess the responsiveness of this questionnaire to interventions intended to improve the quality of communication.

No association was found between the patient ratings of quality of communication and most of the patient characteristics, including sex, socio-economic status or education. There was also no association between the QOC summary score and physician characteristics, including sex, age, years in practice and specialty. However, it is important to note that the small sample size in this study may limit the ability to find small but important differences in assessment of quality of communication. An association was found between depressive symptoms and the QOC summary score, such that the higher the burden of depressive symptoms, the lower the patient ratings of the quality of the physician's communication about end-oflife care. In this study, it can not be determined whether this association reflects poorer quality of communication about end-of-life care with these patients or that patients rate this communication more critically due to their depressive symptoms. Future studies are needed to distinguish these possibilities.

The present study has a number of other important potential limitations. First, the overall participation rate was $<50 \%$. It is likely that patients who do not wish to participate in a study concerning communication with their physician may differ from those that are willing to participate. For example, patients unwilling to participate may be less willing to discuss end-of-life care with their physician. Since communication about end-of-life care may need to occur even with patients less willing to have such communication, understanding the perspectives of these patients is extremely important. Prior research has also found relatively low participation rates for interviews or surveys regarding endof-life care [47]. Although there is no ethical alternative to studying only those willing to participate, future studies may find ways to make participation more attractive or interesting to these patients. The study presented here showed an important difference in participation rates between the two methods used for recruitment. The more resource-intensive method of having a clinician familiar to the patient introduce the study produced a much higher participation rate than the less resource-intensive mailing method. A second limitation of this study is that the use of a questionnaire for patients' assessment, by design, assesses only patients' perspective on patient-physician communication. It may be the case that patients rate a physician's communication highly because they don't have experiences or a frame of reference that allows them to see the short-comings of this communication. In addition, there may be aspects of patient-physician communication that might represent high-quality communication but might not be associated with higher patient satisfaction ratings. Although patient ratings of quality are not the only way to evaluate this communication, the current authors believe that it represents an important perspective that should be included. It also has the advantage of being less resource intensive than expert evaluation of videotapes [46]. Third, some physicians were represented more than once; however, the majority of physicians had only one patient in this study and the QOC score was not different between those with one patient and those with more than one, making it unlikely that this would be an important source of confounding. Finally, this study took place in one city in the USA, and there may be important regional, cultural and national differences in the way that healthcare is delivered or perceived that may affect patients' assessment of the quality of communication about end-of-life care. Further study is needed to understand these differences.

In conclusion, this study describes the specific components of the quality of patient-physician communication about endof-life care from patients' perspectives and suggests that there are three specific areas which need to be improved in respect to communication with patients with chronic obstructive pulmonary disease, as follows: talking about prognosis, talking about dying, and talking about spirituality and religion. These areas provide specific target areas for quality improvement efforts and future research. Studies are needed to identify the most feasible and effective way to improve these aspects of communication about end-of-life care between patients, physicians and other healthcare providers. This study also suggests that the quality of communication questionnaire may be a useful tool for evaluating interventions to improve communication about end-of-life care.

\section{References}

1. Pauwels RA, Buist AS, Calverley CR, Hurd SS, on behalf of the GOLD Scientific Committee. Global strategy for the 
diagnosis, management, and prevention of Chronic Obstructive Pulmonary Disease, NHLBI/WHO Workshop Summary. Am J Respir Crit Care Med 2001; 163: 1256-1276.

2. Mannino DM. COPD: epidemiology, prevalence, morbidity and mortality, and disease heterogeneity. Chest 2002; 121: 121S-126S.

3. The SUPPORT principal investigators. A controlled trial to improve care for seriously ill hospitalized patients: the study to understand prognoses and preferences for outcomes and risks of treatments (SUPPORT). JAMA 1996; 274: 15911598.

4. Field MJ, Cassel CK. Approaching Death: Improving Care at the End of Life. Institute of Medicine Report. Washington, DC, National Academy Press, 1997.

5. Council on Scientific Affairs AMA. Good care of the dying patient. JAMA 1996; 275: 474 478 .

6. Claessens MT, Lynn J, Zhong Z, et al. Dying with lung cancer or chronic obstructive pulmonary disease: insights from SUPPORT. J Am Geriatr Soc 2000; 48: S146-S153.

7. Gore JM, Brophy CJ, Greenstone MA. How do we care for patients with end stage chronic obstructive pulmonary disease (COPD)? A comparison of palliative care and quality of life in COPD and lung cancer. Thorax 2000; 55: 10001006.

8. Heffner JE, Fahy B, Hilling L, Barbieri C. Outcomes of advance directive education of pulmonary rehabilitation patients. Am J Respir Crit Care Med 1997; 155: 1055-1059.

9. Heffner JE, Fahy B, Hilling L, Barbieri C. Attitudes regarding advance directives among patients in pulmonary rehabilitation. Am J Respir Crit Care Med 1996; 154: 17351740.

10. Curtis JR, Wenrich MD, Carline JD, Shannon SE, Ambrozy DM, Ramsey PG. Patients' perspectives on physicians' skills at end-of-life care: differences between patients with COPD, cancer, and AIDS. Chest 2002; 122: 356-362.

11. Curtis JR, Patrick DL. Barriers to communication about end-of-life care in AIDS patients. J Gen Intern Med 1997; 12: 736-741.

12. Curtis JR, Patrick DL, Caldwell E, Greenlee H, Collier AC. The quality of patient-clinician communication about endof-life care: a study of patients with AIDS and their primary care clinicians. AIDS 1999; 13: 1123-1131.

13. Curtis JR, Wenrich MD, Carline JD, Shannon SE, Ambrozy DM, Ramsey PG. Understanding physicians' skills at providing end-of-life care: perspectives of patients, families, and health care workers. J Gen Intern Med 2001; 16: 4149.

14. Wenrich MD, Curtis JR, Ambrozy DM, et al. Provision of emotional support and personalized care by physicians to patients nearing the end of life. J Pain Symptom Manage 2003; 25: 236-246.

15. Glaser BG, Strauss AL. Discovery of Grounded Theory. Chicago, Adline Publishing Company, 1967.

16. Strauss AL, Corbin J. Basics of Qualitative Research: Techniques and Procedures for Developing Grounded Theory. Thousand Oaks, Sage Publications, 1998.

17. Denzin NK, Lincoln YS. The Handbook of Qualitative Research. Thousand Oaks, Sage Publications, 1994; pp. 576.

18. https//depts.washington.edu/eolcare/ Date last updated: 31 April 2004. Date last viewed: 21 May 2004.

19. Radloff LS. The CES-D scale: a self report depression scale for research in the general population. Appl Psychol Meas 1977; 1: 385-401.

20. Comstock GW, Helsing KJ. Symptoms of depression in two communities. Psychol Med 1976; 6: 551-564.

21. American Thoracic Society. Standards for the diagnosis and care of patients with chronic obstructive pulmonary disease. Am J Respir Crit Care Med 1995; 152: S77S120.

22. Billings JA, Block S. Palliative care in undergraduate medical education: status report and future directions. JAMA 1997; 278: 733-738.
23. Buckman R. Breaking bad news: why is it still so difficult? BMJ 1984; 288: 1697-1599.

24. Buckman R. How to Break Bad News. Baltimore, Johns Hopkins University Press, 1992.

25. Fallowfield L. Giving sad and bad news. Lancet 1993; 341: 476-478.

26. Ptacek JT, Eberhardt TL. Breaking bad news: a review of the literature. JAMA 1996; 276: 496-502.

27. Quill TE, Townsend P. Bad news: delivery, dialogue, and dilemmas. Arch Intern Med 1991; 151: 463-468.

28. Lo B, Quill T, Tulsky JA, for the ACP-ASIM End-of-Life Care Consensus Panel. Discussing palliative care with patients. Ann Intern Med 1999; 130: 744-749.

29. Guthrie SJ, Hill KM, Muers ME. Living with severe COPD: a qualitative exploration of the experience of patients in Leeds. Respir Med 2001; 95: 196-204.

30. Bailey PH, Tilley S. Storytelling and the interpretation of meaning in qualitative research. $J$ Adv Nurs 2002; 38: 574-583.

31. Wenrich MD, Curtis JR, Shannon SE, Carline JD, Ambrozy DM, Ramsey PG. Communicating with dying patients within the spectrum of medical care from terminal diagnosis to death. Arch Intern Med 2001; 161: 868-874.

32. Jenkins V, Fallowfield L, Saul J. Information needs of patients with cancer: results from a large study in UK cancer centres. Br J Cancer 2001; 84: 48-51.

33. Weeks JC, Cook EF, O'Day SJ, et al. Relationship between cancer patients' predictions of prognosis and their treatment preferences. J Am Med Assoc 1998; 279: 1709-1714.

34. Christakis NA. Death Fortold: Prophecy and Prognosis in Medical Care. Chicago, University of Chicago Press, 1999.

35. Miyaji NT. The power of compassion: truth-telling among American doctors in the care of dying patients. Soc Sci Med 1993; 36: 249-264.

36. The A-M, Hak T, Koeter G, van der Wal G. Collusion in doctor-patient communication about imminent death: an ethnographic study. BMJ 2000; 321: 1376-1381.

37. Ehman JW, Ott BB, Short TH, Ciampa RC, HansenFlaschen J. Do patients want physicians to inquire about their spiritual or religious beliefs if they become gravely ill? Arch Intern Med 1999; 159: 1803-1806.

38. King DE, Bushwick B. Beliefs and attitudes of hospital inpatients about faith healing and prayer. J Fam Pract 1994; 39: $349-352$.

39. Anderson JM, Anderson LJ, Felsenthal G. Pastoral needs for support within an inpatient rehabilitation unit. Arch Phys Med Rehabil 1993; 74: 574-578.

40. Sprung CL, Cohen SL, Sjokvist P, et al. End-of-life practices in European intensive care units: the Ethicus Study. JAMA 2003; 290: 790-797.

41. Post SG, C.M. P, Larson DB. Physicians and patient spirituality: professional boundaries, competency, and ethics. Ann Intern Med 2000; 132: 578-583.

42. Lo B, Ruston D, Kates LW, et al. Discussing religious and spiritual issues at the end of life: a practical guide for physicians. JAMA 2002; 287: 749-754.

43. Tulsky JA, Chesney MA, Lo B. How do medical residents discuss resuscitation with patients? J Gen Intern Med 1995; 10: $436-442$

44. Tulsky JA, Fischer GS, Rose MR, Arnold RM. Opening the black box: how do physicians communicate about advance directives? Ann Intern Med 1998; 129: 441-449.

45. Fischer GS, Tulsky JA, Rose MR, Siminoff LA, Arnold RM. Patient knowledge and physician predictions of treatment preferences after discussion of advance directives. J Gen Intern Med 1998; 7: 447-454.

46. Fallowfield L, Jenkins V, Farewell V, Saul J, Duffy A, Eves R. Efficacy of a Cancer Research UK communication skills training model for oncologists: a randomized controlled trial. Lancet 2002; 359: 650-656.

47. Fowler JF, Coppola KM, Teno JM. Methodological challenges for measuring quality of care at the end of life. J Pain Symptom Manage 1999; 17: 114-119. 